\title{
THREE CASES OF ACHONDROPLASIA WITH NEUROLOGICAL COMPLICATIONS
}

\author{
BY \\ JOHN D. SPILLANE \\ From the Department of Neurology and Neurosurgery, United Cardiff Hospitals
}

The role played by congenital malformations of the skull and spine in the production of lesions of the central nervous system has been increasingly appreciated in recent years. In the skull premature synostosis of the sutures of the vault (craniostenosis) can lead to optic atrophy and symptoms of intracranial hypertension. Hydrocephalus and compression of the brain stem and upper cervical cord can result from deformities of the base of the skull, such as platybasia and narrowing of the foramen magnum. In the spine congenital deformities, such as hemivertebrae, absence of cervical segments, scoliosis, and kyphosis, may also result in cord compression in adult life.

In this paper attention is drawn to the possible effects on the nervous system of achondroplasia. This condition of foetal chondrodystrophy is well known and is characterized by failure of endochondral ossification. It results in a striking disproportion of the body ; a large head, short limbs, and a spine of relatively normal length.

The complications of hydrocephalus and compression of the spinal cord and cauda equina are demonstrated in the following case reports.

Case 1.-This was a man aged 40 , an achondroplasic dwarf. He was $4 \mathrm{ft}$. $7 \frac{1}{2}$ in. high, with a head circumference of 23 in. He was of average intelligence. His father was similarly afflicted and in his forties developed paralysis of the legs, for which a spinal operation was performed in 1913. The patient stated that some recovery took place, but he died a few years later when paralysis of the lower limbs was then complete.

The patient was well until January, 1951, when he began to suffer from pains in the lumbo-sacral region which later radiated down the outer aspects of both thighs. Six months afterwards he felt tingling sensations in both feet and two weeks before admission to hospital in July, 1951, he felt that his buttocks and the soles of his feet were numb. There had been some difficulty in micturition for seven days.

On examination speech was normal. His gait was waddling with noticeable weakness of dorsiflexion of the feet. The cranial nerves were normal. The arms were normal. Abdominal reflexes were present. Power in both legs was considerably reduced, especially below the knees, with bilateral partial foot drop. Knee and ankle jerks were absent on each side. Plantar reflexes were flexor. There was no wasting or fibrillation. Sensation was moderately impaired bilaterally (L.5, S.1, and 2), and analgesia was marked (S.3, 4, and 5) bilaterally. There was lumbar kyphosis (Fig. 1) with slight generalized restriction of spinal movements.

Lumbar puncture at L.4-5 showed clear orange coloured fluid (protein 2,060 mg. per $100 \mathrm{ml}$. ) and absolute block on bilateral jugular compression.

\section{Radiological Examination.-}

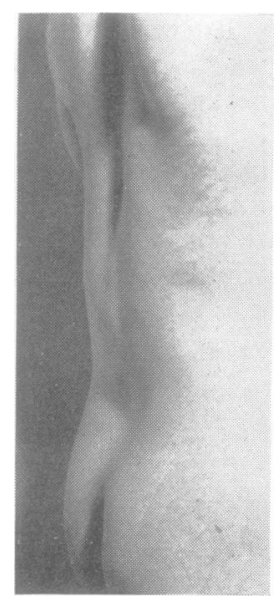

FIG. 1.-Gibbus deformity of lumbar
spine in Case 1.

The patient had a fairly large head, with a shallow posterior fossa, a normal foramen magnum, no platybasia, and small facial bones with a slight degree of hypertelorism.

Cisternal air encephalography showed slight sym-

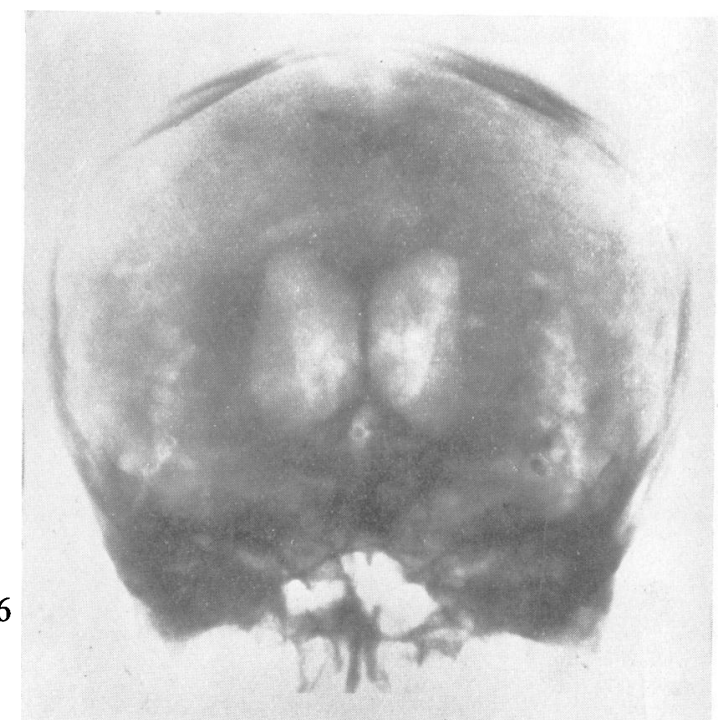

FIG. 2.-Air encephalogram showing dilatation of lateral ventricles in Case 1 . 
metrical ventricular dilatation (Fig. 2) including the third ventricle. The aqueduct and fourth ventricles were normal.

The cervical spine was normal, except for loss of the lordotic curve. The dorsal spine was normal. The lumbar spine had marked kyphosis centred at L.2 (Fig. 3), the

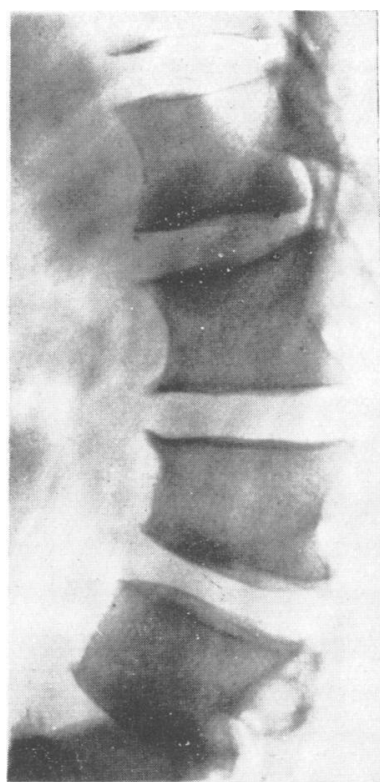

Fig. 3.-Lumbar spine ; kyphosis, wedging of L.V.2, wide disc spaces, and concave posterior borders of vertebral bodies in Case 1.

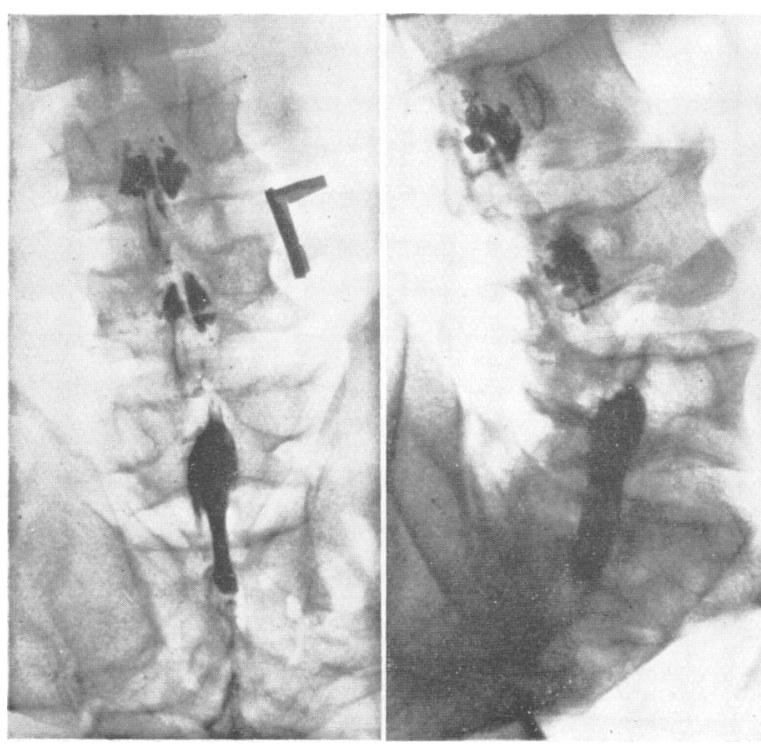

FIG. 4a and b.-Lumbar myelogram; myodil arrested opposite bodies and discs of L.V. 3, 4, and 5 in Case 1 . the evidence of block at these levels. It was concluded that there was cauda equina compression opposite the bodies and discs L.3, 4, and 5 .

Laminectomy.--Professor Lambert Rogers performed a laminectomy at L.2, 3, 4, and 5. The dural tube was displaced posteriorly at L.2, 3, and 4 by massively protruding intervertebral discs which were removed. The dura was then opened and the cauda equina found to be slack and relieved of pressure.

Progress.-Following this operation the patient made good progress and has now returned to his work and regained good function in both legs. The reflexes are still absent but the sensory disturbance has practically cleared.

Case 2.-This woman was aged 37 years and was a typical achondroplasic dwarf (Fig. 5), standing $4 \mathrm{ft} .5$ in. high with a head circumference of 24 in. She was of good intelligence, and had no family history of dwarfism.

She was well until nine years ago when she first noticed numbness of the left foot. Subsequently she developed low back pain with radiation of sciatic distribution. Weakness of the legs developed two years ago with bilateral foot drop. She had no symptoms referable to the head, trunk, neck, or upper limbs. Precipitancy and frequency of micturition were present. She had worn a caliper on the left leg for the past year.

On examination it was seen that she was only able to walk slowly .with the aid of two sticks. Speech was normal. The cranial nerves were normal. The upper limbs were normal. The upper abdominal reflex was present, the lower reduced. There was bilateral foot drop with corresponding muscular atrophy and loss of both ankle jerks. The right knee jerk was reduced, the left normal. Plantar reflexes were flexor. All movements at the ankle were weak, but those at the hip and knee were

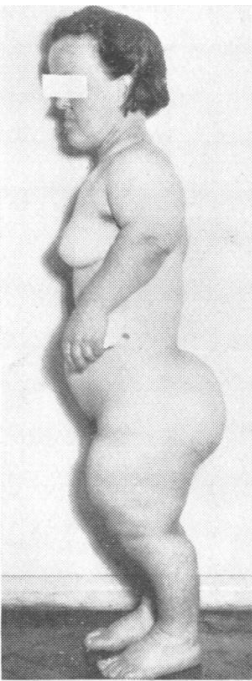

FIG. 5.-Slight dorsolumbar kyphosis and horizontal sacrum in Case 2. nearly normal. All forms of cutaneous sensation below both knees were markedly impaired. Between the knees and groin pin-prick and temperature differences were not fully appreciated. Vibration and joint position sense were grossly defective in the feet.

Lumbar puncture at L.3-4 demonstrated absolute manometric block on bilateral jugular compression. The cerebrospinal protein was $575 \mathrm{mg}$. per $100 \mathrm{ml}$.

Radiological Examination.--The skull was large, with a normal foramen magnum and no platybasia.

Cisternal air encephalography showed marked symmetrical dilatation of the lateral ventricles (Fig. 6) with 


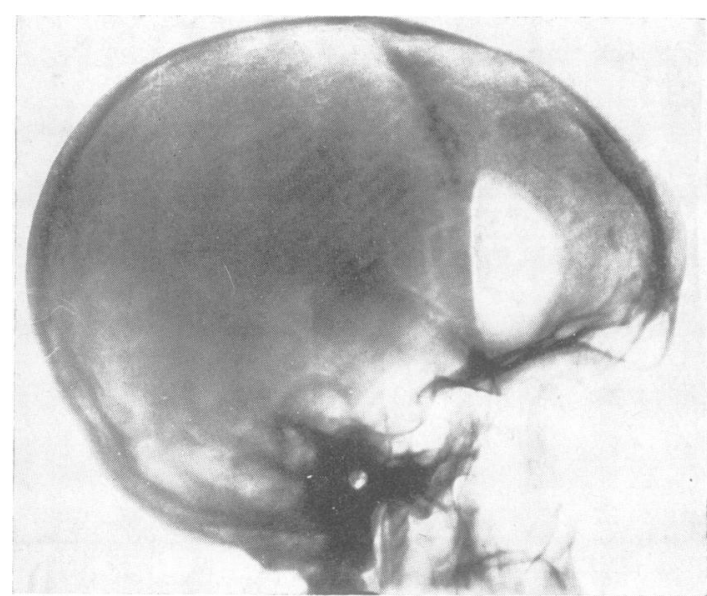

FIG. 6.-Air encephalogram of Case 2 showing dilatation of lateral ventricles.

some dilatation also of the third ventricle, the aqueduct, and the fourth ventricle. No other deformity or displacement was shown. In the cervical spine the vertebrae were tall but there was no other abnormality. There was lower dorsal lordosis only. There was slight dorso-lumbar kyphosis (Fig. 7) with exaggerated lower lumbar lordosis. The posterior surfaces of the vertebral bodies were concave with large intervertebral disc spaces, and osteophytes at L.1-2 and L. 2-3. The sacrum lay horizontally. Pedicles and interpedicular widths

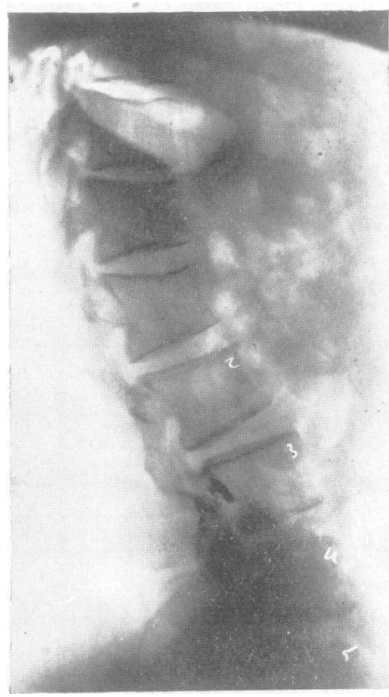

FIG. 7.--Lumbar myelogram showing slight dorso-lumbar kyphosis, lumbar lordosis, concave posterior borders of vertebral bodies, wide disc spaces anteriorly, myodil arrested at L.V.4 with complete block at L.V.3 in Case 2. were normal.

Lumbar myelography showed partial block at L.4 and complete block at L.3.

Myodil was arrested at the L.1-2 disc space. A pool of myodil collected opposite each vertebral body from D.8 to L.1, and the myodil column was interrupted opposite each disc between these levels (Figs. 8a and b).

It was concluded that there were multiple intervertebral disc protrusions with cauda equina compression.

Laminectomy.A laminectomy performed by Mr. Charles Langmaid disclosed a narrow spinal canal with multiple disc protrusions and cauda equina compression. The protruding material was removed.

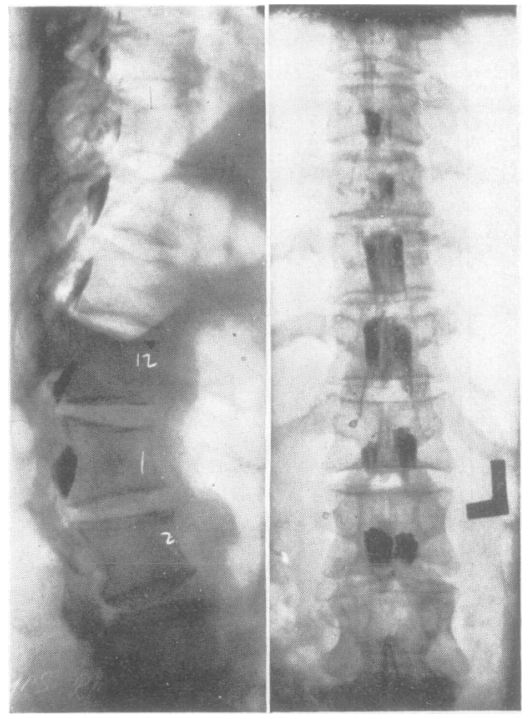

FIG. 8a and b.-Cisternal myelogram of Case 2 showing myodil arrested at L.V.1-2 disc space with pool of myodil opposite each vertebral body from D.8 to L.1.

The patient's subsequent progress was slow. She has not regained power in the left foot but there is moderate improvement in the power of the right lower limb and her gait is better.

Case 3. - This was a man aged 29, a typical achondroplasic dwarf, standing $4 \mathrm{ft}$. $10 \mathrm{in}$. high, with a head circumference of 24.5 in. His intelligence was below average. He had no family history of dwarfism.

The patient was well until two years ago when he first began to notice weakness and stiffness of the lower limbs. At first there was dragging and periodic trembling of the left leg. Later both legs became weak and he found increasing difficulty in walking. He was forced to give up his work three months ago. Recently he had had some pain in the cervico-occipital region and periodic substernal discomfort.

On examination it was seen that he was unable to walk without assistance and had a spastic tetraplegia. The cranial nerves were normal. Neck movements were normal. There was slight upper lumbar kyphosis. Power in both arms was markedly reduced but in the legs power was little affected. The biceps, triceps, and radial reflexes were grossly exaggerated, with brisk finger reflexes. Abdominal reflexes were absent and there was bilateral knee and ankle clonus. There were extensor plantar responses bilaterally. There was no obvious wasting. Coordination was normal. Cutaneous sensation was considerably reduced from C.2 to D.1, but below this level there was only slight loss of superficial sensibility. Vibration sensation was absent in the lower limbs and not normally perceived below mid-thoracic level. It was also reduced in the fingers and hands. 
Lumbar puncture at L.4-5 gave a clear fluid with normal manometric tests when the head was in the midposition. When the head was either flexed or extended more than $20^{\circ}$ from the midline position complete spinal manometric block was revealed. Cerebrospinal protein was $280 \mathrm{mg}$. per $100 \mathrm{ml}$.

Radiological Examination.-The skull had a large vault, the base smaller than normal (Fig. 9). The clivus was steep and short. The posterior fossa was shallow. The squamous occiput appeared to overhang the atlas. There was slight hypertelorism, but no evidence of platybasia. The foramen magnum was normal.

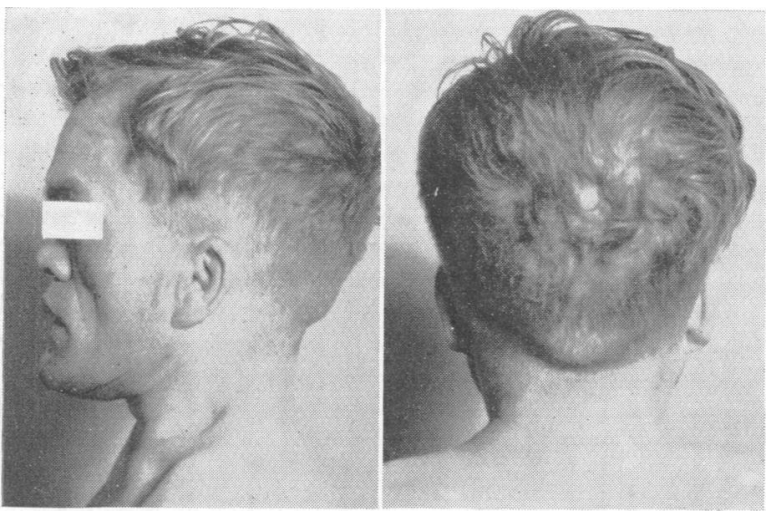

Fig. 9.-Large head, depressed nasal bridge, short neck of Case 3.

A lumbar air encephalogram showed moderate symmetrical dilatation of the lateral ventricles (Fig. 10) and slight dilatation of the aqueduct and third ventricle. Filling of the fourth ventricle in the brow-down position was not possible.

The vertebral bodies were shallow and broad (resembling an infantile type of spine). With flexion of the head

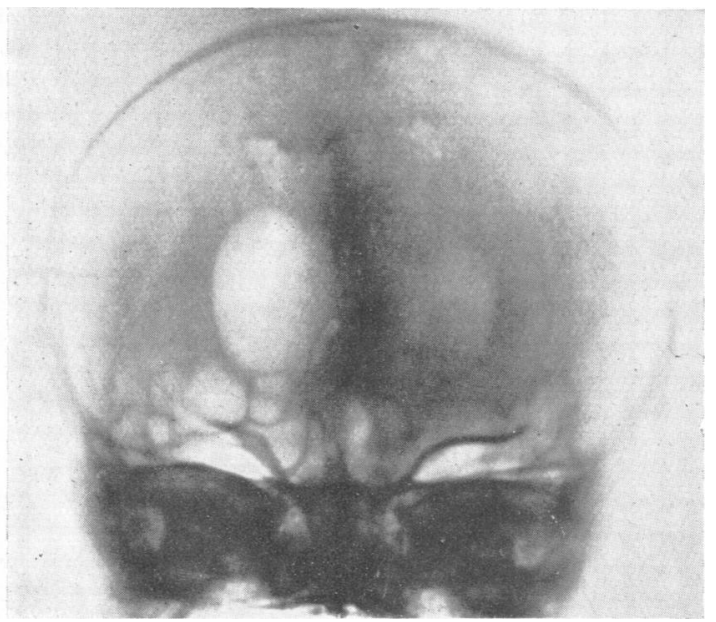

Fig. 10.-Air encephalogram of Case 3 showing dilatation of lateral ventricles.
Fig. 11.-Lumbar spine showing upper lumbar kyphosis, wedging of L.V.2, concave posterior borders of vertebral bodies which are shallow and broad in Case 3 .

there was subluxation of the axis on C.3. The posterior surface of the body of the axis was $4 \mathrm{~mm}$. anterior to that of C.3. There was slight dorsal lordosis and upper lumbar kyphosis (Fig. 11). The L.2 vertebra was wedgeshaped. The pedicles and interpedicular widths were normal. The posterior surfaces of the bodies of the lumbar vertebrae were concave and the intervertebral disc spaces were large.

Lumbar Myelography.In the lumbar region there was constriction of the myodil column opposite each intervertebral disc space but without any actual hold-up. In the cervical region there was indentation of the anterior surface of the myodil column opposite each disc space. Confirmation of the presence of subluxation of the axis on C.3 was obtained (Fig. 12). The myodil outlining the anterior wall of the thecal space was separated from the posterior surface of the axis by a distance of $5 \mathrm{~mm}$., as compared with $2 \mathrm{~mm}$. between it and the posterior surface of the body of C.3. No bony exostosis could be demonstrated.

\section{Discussion}

Paraplegia.-There has been some dispute about the condition of the vertebral column in achondroplasia. Some authors have described only the characteristic lumbar lordosis and tilting of the sacrum but Breus and Kolisko (1900) and Donath and Vogl (1925) showed that abnormalities of the spine were a regular occurrence and that there were changes in the individual vertebrae and in the spine as a whole. They noted a decrease in the height of the vertebral bodies and shortness of the pedicles. The latter resulted from premature synostosis of the centres of ossification of the body with those of the lamina. The spinal canal was narrowed in one or all of its diameters and this led to tight encasement of the normally developed spinal cord. Donath and Vogl also pointed out that in achondro- 


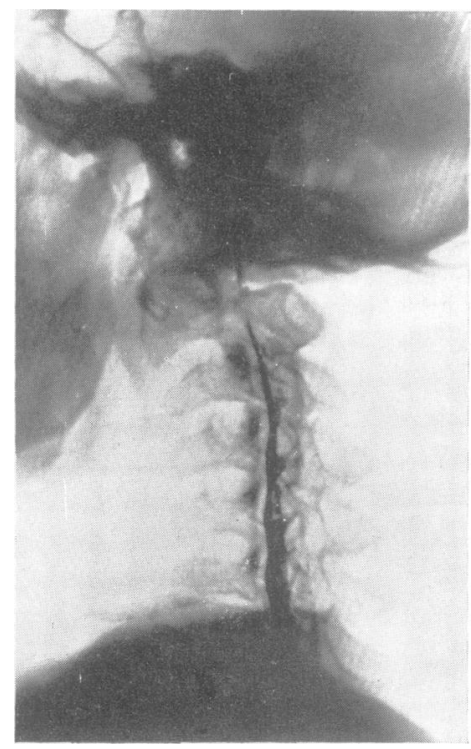

Fig. 12.-Lumbar myelogram of Case 3 showing subluxation of atlas on C.V.3.

plasia the normal developmental " unrolling" of the spine is incomplete owing to the absence of a well organized and directed growth of cartilage ; straightening is not completed. The infant with achondroplasia is born with some degree of dorsolumbar kyphosis and a gibbus may develop during life. They reported the case of a 57-year-old male adult achondroplasic who developed a spastic paraplegia with urinary retention. The first lumbar vertebra was wedge-shaped and displaced posteriorly so that the twelfth thoracic and second lumbar vertebrae articulated with each other anteriorly. Spinal manometry at L. 4-5 was normal; the cerebrospinal fluid was normal. The patient died four years later. At necropsy the constriction of the spinal canal was pronounced and resulted from shortness of the pedicles and "mushrooming" of the superior articular process and encroachment on the spinal canal. The cord itself was indented and softened above the gibbus.

In $1949 \mathrm{Vogl}$ and Osborne reported another case of cord compression in an achondroplasic male aged 30 years. He developed pain in the back and legs, unsteadiness of gait, urinary incontinence, and sexual impotence. There were no definite motor or sensory changes but the knee and ankle jerks were hyperactive. The twelfth thoracic vertebra was wedged and there was marked osteophyte formation between the eleventh and twelfth vertebrae. Lumbar puncture (L.2-3) showed that there was partial manometric block; the cerebrospinal fluid was $80 \mathrm{mg}$. per $100 \mathrm{ml}$. Myeloscopy disclosed narrowing of the spinal canal. Opaque myelo- graphy indicated partial block at Th.11-12. Laminectomy confirmed these findings and was followed by relief of symptoms.

Up to 1949 Vogl and Osborne said that there had been 10 published cases (including their own) of " transverse myelopathy" in achondroplasic dwarfs. Few of these reports are at all complete. I have come across one further report by Poynton (1907) in Allbutt and Rolleston's System of Medicine. Poynton's patient was 15 years of age, 41 in. in height, and began to develop a spastic paraplegia in his thirteenth year. His mental state was good. The cause of the paraplegia cannot be deduced in the case reports of Parhon and Schunda (1913) and of Parhon and Zalpachta (1905), two cases; of Zosin (1910), of Falta (1913), of Maas (1920), and of Keményffi (1924).

In the two remaining reports neurological and radiological findings are recorded ; manometry and myelography were not performed.

Albrecht and Ranzi (1926) published the case of an achondroplasic dwarf, aged 46 years, who developed complete spastic paraplegia with incontinence over a 10-year period. Lumbar puncture yielded repeated dry taps and there was wedging with osteophyte formation of the twelfth thoracic vertebra. Laminectomy (Th.10, 11, and 12) confirmed the presence of cord compression; the spinal canal appeared too tight for the dural sac which did not pulsate and bulged from the operative gap. There was considerable improvement following this decompression laminectomy.

In the second case (Freund, 1933) the patient, aged 21 years, developed spastic weakness of the lower limbs, with pain in the back and thighs, over a period of one year. There was sensory loss below L.3 on the left side. Sphincters were unaffected. Lumbar puncture was not done. The second lumbar vertebra was wedge-shaped and there was a severe gibbus deformity. Traction gave temporary relief. Laminectomy (Th.12-L2) revealed severe angulation of the cord and cauda equina, with a non-pulsatile tight dura. The latter was not opened. A flaccid paraplegia with incontinence followed the operation and a second exploration was undertaken to exclude the presence of a haematoma. None was found. The author felt that a simple congenital stenosis of the spinal canal was not the explanation for the paraplegia, but that cord compression was subsequent to encroachment of the spinal canal by marginal exostoses. As in Donath and Vogl's case, the site of the cord compression was above the level of the gibbus.

Neurological complications may also arise in the condition known as hereditary deforming 
dyschondroplasia (Slepian and Hamby, 1951). Compression of the spinal cord, the brachial plexus, and various nerves by bony exostoses have been recorded.

In Cases 1 and 2 of the present report cauda equina compression occurred at several levels as a result of massive protrusion of lumbar intervertebral discs. In Case 3 there was subluxation of the second cervical vertebra upon the third, and manometric spinal block was produced by slight flexion or extension of the neck. In the first two cases the bodies of the cervical vertebrae were rather tall. In all three the posterior surfaces of the bodies of the lumbar vertebrae were concave and the adjacent intervertebral disc spaces were abnormally wide. These appearances in the cervical and lumbar spine were also observed in five out of six further achondroplasic adults. One of these complained of pain and stiffness in the back and thighs but there were no neurological abnormalities. In another case the right knee and ankle jerks were markedly exaggerated and the plantar reflex on that side was questionably extensor. In a third case there was an isolated extensor plantar response but it was not constantly demonstrable.

Hydrocephalus.-Marie (1900) considered that the enlargement of the head was probably due to the presence of hydrocephalus although he lacked necropsy evidence. Jansen (1912) concluded that shortening of the base of the skull involved the oral cavity and the sagittal dimensions of the foramen magnum. He quoted Virchow, who considered that kyphosis basis cranii was a characteristic feature of the disease. Jansen showed that the brachycephalic configuration of the skull in achondroplasia was also contributed by the increased width of the skull. Two of his five cases had hydrocephalus which he attributed to an impaired outflow of cerebrospinal fluid from the ventricular system caused by brain stem compression and distortion. Dandy. (1921) supported this explanation. Hydrocephalus was present in his two cases and in one was demonstrated by ventriculography to be of the communicating type. He thought that the chondrodystrophy at the base of the skull causes obstruction in the posterior fossa and the development of ventricular dilatation. In some cases it has been demonstrated that the hydrocephalus is present at birth (Russell, 1949), and Dandy suggested that growth of the base of the skull after birth might lead to some relief of the hydrocephalus. In a recent examination of an achondroplasic infant, stillborn at the eighth month, I was unable to find any evidence of hydrocephalus.
In each of the three cases which form the basis of the present report, air encephalography revealed the presence of internal hydrocephalus. The dilatation of the lateral ventricles was symmetrical and was slight in Case 1, marked in Case 2, and moderate in Case 3. In Case 1 the dilatation involved the third ventricle; the aqueduct and the fourth ventricle were normal. In Case 2 the third and fourth ventricles and the aqueduct were involved in the dilatation. In Case 3 the aqueduct and third ventricle were dilated but filling of the fourth ventricle could not be obtained. Intelligence was average in Case 1, high in Case 2, and below average in Case 3.

The lack of correlation between the degree of hydrocephalus and the intelligence was noticeable in Case 2.

As Jansen stressed, there are degrees of achondroplasia and slight examples of the disease may not be recognized. It is conceivable that the chondrodystrophic disturbance may at times be almost confined to the base of the skull. Hydrocephalus may then develop and the essential fact of achondroplasia may pass undetected.

\section{Summary}

The neurological complications which arose in three achondroplasic adults are described. Internal hydrocephalus was present in each case and probably resulted from the characteristic shortness of the base of the skull. There was no evidence of platybasia nor of any deformity of the foramen magnum.

Two of the patients developed severe cauda equina compression as a result of multiple massive lumbar intervertebral disc protrusions. At operation it was also observed that the spinal canal was generally narrowed. The achondroplasic father of one of these cases had also developed paraplegia requiring laminectomy. The third patient had a spastic tetraplegia with subluxation of the second cervical vertebra upon the third. There was spinal manometric block when the neck was slightly flexed or extended. No bony exostosis could be demonstrated in the upper cervical level.

In Cases 1 and 2 the bodies of the cervical vertebrae were tall. In Case 3 all the vertebral bodies were shallow and broad. In all three cases the posterior surfaces of the bodies of the lumbar vertebrae were concave and the intervertebral disc spaces were unusually wide. Similar radiological signs were observed in varying degree in five out of six other achondroplasic adults. 
None of the three patients with spinal complications had ever been engaged in tumbling or acrobatics.

I am grateful to Professor Lambert Rogers, Mr. Charles Langmaid, and Dr. Geoffrey H. T. Lloyd for their observations and assistance, and to Dr. Arthur M. Jones for the radiographs. Clinical photographs were taken by Mr. H. A. Griffiths, of the Department of Clinical Photography, Llandough Hospital.

\section{REFERENCES}

Albrecht, O., and Ranzi, E. (1926). Wien. klin. Wschr., 39, 1241.

Breus, C., and Kolisko, A. (1900). (Breus and Kolisko.) Die pathologischen Beckenformen, vol. 1, pp. 267 and 313. Leipzig. Quoted by Vogl and Osborne.
Dandy, W. E. (1921). Bull. Johns Hopk. Hosp., 32, 5.

Donath, J., and Vogl, A. (1925). Wien. Arch. inn. Med., 10, 1.

Falta, W. (1913). Quoted by Vogl and Osborne.

Freund, E. (1933). Arch. Surg., Chicago, 27, 859.

Jansen, M. (1912). Achondroplasia: its Nature and its Cause. Leiden.

Keményffi, A. (1924). Quoted by Vogl and Osborne.

Maas, O. (1920). Z. ges. Neurol. Psychiat. (orig.), 57, 196. Quoted by Vogl and Osborne.

Marie, P. (1900). Presse méd., 8 (2), 17.

Parhon, C., and Schunda, A. (1913). N. Iconogr. Salpêt., 26, 185. —, and Zalplachta, - (1905). Ibid., 18, 539.

Poynton, F. J. (1907). In Allbutt and Rolleston's System of Medicine, 2nd ed., vol. 3, p. 117.

Russell, D. (1949). Spec. Rep. Ser. med. Res. Coun., Lond., No. 265

Slepian, A., and Hamby, W. B. (1951). J. Neurosurg., 8, 529.

Vogl, A. and Osborne, R. L. (1949). Arch. Neurol. Psychiat., Chicago, 61, 644.

Zosin, P. (1910). N. Iconogr. Salpêt., 23, 31. Quoted by Vogl and Osborne. 